\title{
UNIVERSAL HEALTH COVERAGE FOR
} INCLUSIVE AND SUSTAINABLE DEVELOPMENT: A SYNTHESIS OF 11 COUNTRY CASE STUDIES

Akiko Maeda, Edson Araujo, Cheryl Cashin, Joseph Harris, Naoki Ikegami, and Michael R. Reich (org.), International Bank for Reconstruction and Development / The World Bank <http://dx.doi.org/10.1596/978-1-4648-0297-3>

${ }^{1}$ Universidade de São Paulo. São Paulo/SP, Brasil.

Correspondência: Sueli Gandolfi Dallari. E-mail: sdallari@usp.br.

Recebido em: 01/02/2015. 
Trata-se de obra que pretende responder a dois interesses postos ao grupo Banco Mundial. Inicialmente, aquele que se seguiu à publicação, em 2010, do "Relatório Mundial da Saúde: financiamento dos sistemas de saúde": o caminho para a cobertura universal. A isso se somou o desejo do Japão de comemorar os 50 anos de seu sistema de cobertura universal de saúde. O grupo Banco Mundial juntou-se ao Japão para conceber o estudo multicêntrico, considerando países com diversos níveis de desenvolvimento. Foram selecionados Bangladesh, Brasil, Etiópia, França, Gana, Indonésia, Japão, Peru, Tailândia, Turquia e Vietnã, países com grande diversidade geográfica, econômica e histórica.

Os respectivos dados foram reunidos em três temas: (1) política econômica e processo político para adotar, alcançar e sustentar a cobertura universal de saúde (UHC, na sigla em inglês); (2) políticas de financiamento tendentes a reforçar a cobertura de saúde; e (3) recursos humanos para as políticas destinadas a alcançar a UHC. Foram identificados três processos políticos diferentes para a UHC, comportando distintos desafios de política econômica: (a) adoção dos objetivos de UHC; (b) expansão da cobertura de saúde; e (c) redução das desigualdades relacionadas à cobertura de saúde. Quanto às políticas de financiamento em saúde, $o$ estudo analisou três hipóteses: (a) aumentar as receitas para expandir e sustentar a cobertura; (b) evitar desperdício; e (c) conseguir um sistema efetivo de seleção dos riscos e redistribuição dos recursos para garantir equidade e proteção financeira. E, quanto aos recursos humanos, verificou-se que todos os países enfrentam desafios em (a) produção; (b) desempenho; e (c) distribuição dos trabalhadores de saúde para a UHC.

A questão fundamental que permanece velada durante toda a obra deveria ser desvendada já no capítulo inicial. De fato, é dada como de aceitação tranquila a definição da UHC como "uma condição na qual todas as pessoas que precisam de cuidados de saúde (prevenção, promoção, tratamento, reabilitação e cuidados paliativos) os recebam, sem dificuldade financeira indevida". Ora, ninguém duvida ser direito humano fundamental o acesso, sempre que necessário, a cuidados de saúde de qualidade para todo e cada um dos seres humanos. Questiona-se, entretanto, a conveniência da existência de alguma barreira financeira aceitável que dificulte tal acesso. Afinal, o mundo contemporâneo vive um claro conflito entre o discurso dos direitos humanos e aquele da ordem financeira, que enxerga a atenção à saúde como uma mercadoria. Veja-se, por exemplo, alguns dos argumentos dos detratores da UHC: ela não será capaz de atender aos muitos outros programas de saúde pública, indispensáveis para assegurar "uma visão mais ampla, com um conjunto de objetivos com metas e indicadores de prevenção, tratamento, determinantes sociais, sistemas de saúde, mudanças climáticas e equidade, entre outras preocupações”; ou ainda a constatação de que os programas de ajuste, levando os governos a diminuir gastos públicos e ao desenvolvimento de um setor privado que visa ao lucro, dentro de uma 
lógica de mercado, não produzirão "saúde" . Assim, embora todos concordem que seja necessário estimular os governos a planejar ou prosseguir a transição para o acesso universal a serviços de saúde acessíveis e de qualidade ${ }^{2}$, há ainda intensa disputa a propósito das estratégias a serem adotadas. O primeiro-ministro japonês, ao lembrar, nessa mesma reunião, o sucesso de seu país na melhora da equidade no sistema de saúde, na expansão da cobertura para os cidadãos e no controle do custo dos serviços, não escondeu a estratégia que ele espera ver adotada: o seguro sanitário universal ${ }^{3}$.

Esses importantes argumentos foram decididamente esquecidos na obra em análise, que optou claramente pela fórmula do seguro - como era previsível, dado que o governo japonês foi seu grande financiador. E, embora faça alusão a aspectos correlatos (como a amplitude dos serviços de acordo com a necessidade ou a cobertura de toda a população), seu foco é a proteção financeira contra o pagamento direto pelo serviço de saúde consumido. Assim, o grupo Banco Mundial fixou dois objetivos: o primeiro, relacionado evidentemente à proteção financeira, mira a redução pela metade no número de pessoas empobrecidas pelas despesas diretas de saúde até 2020 (de 50 milhões a 100 milhões de pessoas) e a eliminação desse número até 2030. Ainda sob uma ótica mercadológica, o grupo fixou como segundo objetivo que quatro em cada cinco pessoas vivendo nos países com menor nível de renda tenham acesso aos serviços essenciais de saúde. O grupo Banco Mundial desenvolveu, então, o programa Desafio da Cobertura Universal de Saúde (The Universal Health Coverage Challenge Program, Unico), que consiste na criação de ferramentas para a UHC. Uma delas é a síntese comparativa entre 25 países (prometida para o fim de 2014) e a outra é a Universal Health Coverage Assessment Tool (Unicat), para ajudar os países a avaliar suas forças e fraquezas no processo de executar políticas de UHC.

Especificamente para a obra Universal Health Coverage for Inclusive and Sustainable Development: A Synthesis of 11 Country Case Studies, os 11 países foram colocados em quatro grandes grupos, refletindo os diferentes estágios de adoção, alcance e sustentação da UHC, conforme se verifica na Tabela 1.

Suas conclusões são apresentadas em sete capítulos, dedicados a: $\left(1^{\circ}\right)$ objetivos da UHC; $\left(2^{\circ}\right)$ objetivos, alcance e quadro analítico; $\left(3^{\circ}\right)$ lições emergentes das experiências dos países; $\left(4^{\circ}\right)$ lições da UHC em economia política e processo político; $\left(5^{\circ}\right)$ lições da UHC em financiamento de saúde; $\left(6^{\circ}\right)$ lições da UHC em recursos humanos para a saúde; $\left(7^{\circ}\right)$ pontos-chave e próximos passos.

\footnotetext{
${ }^{1}$ HORTON, Richard. Offline: The advantages of Universal Health. The Lancet, v. 30, n. 9854, p. 1632,10 nov. 2012.

${ }^{2}$ ORGANIZAÇÃO DAS NAÇÕES UNIDAS (ONU). Assembleia Geral $(67,2012)$. Adopting consensus text, General Assembly encourages member states to plan, pursue transition of national health care systems towards universal coverage. (GA/11326) Dec 12, 2012. Disponível em: <http://www.un.org/News/Press/docs/2012/ ga11326.doc.htm2>.

${ }^{3} \mathrm{ABE}$, Shinzo. Comment: Japan's strategy for global health diplomacy: why it matters. The Lancet, v. 382, n. 9896, p. 915-916, 14 sep. 2013.
} 
Tabela 1. Estágios de adoção, alcance e sustentação da UHC.

\begin{tabular}{|c|c|c|c|c|}
\hline Características & Grupo 1 & Grupo 2 & Grupo 3 & Grupo 4 \\
\hline $\begin{array}{l}\text { Status das } \\
\text { políticas } \\
\text { e dos } \\
\text { programas de } \\
\text { UHC }\end{array}$ & $\begin{array}{c}\text { Definição } \\
\text { da agenda: } \\
\text { desenhando } \\
\text { novos } \\
\text { programas e } \\
\text { desenvolvendo } \\
\text { novos sistemas. }\end{array}$ & $\begin{array}{c}\text { Programas } \\
\text { e sistemas } \\
\text { iniciais na praça, } \\
\text { implementação } \\
\text { em progresso: } \\
\text { necessidade } \\
\text { de maior } \\
\text { desenvolvimento } \\
\text { e construção de } \\
\text { capacidade para } \\
\text { atingir a população } \\
\text { remanescente não } \\
\text { coberta. }\end{array}$ & $\begin{array}{l}\text { Forte liderança } \\
\text { política e } \\
\text { demanda popular, } \\
\text { levando a novos } \\
\text { investimentos } \\
\text { e reformas } \\
\text { políticas para a } \\
\text { UHC; sistemas } \\
\text { e programas } \\
\text { desenvolvidos para } \\
\text { atender a novas } \\
\text { demandas. }\end{array}$ & $\begin{array}{c}\text { Sistemas e } \\
\text { programas } \\
\text { maduros; } \\
\text { sistemas } \\
\text { adaptativos } \\
\text { que permitem } \\
\text { ajustamentos } \\
\text { contínuos } \\
\text { para atender } \\
\text { a demandas } \\
\text { mutáveis. }\end{array}$ \\
\hline $\begin{array}{l}\text { Status da } \\
\text { cobertura de } \\
\text { saúde }\end{array}$ & $\begin{array}{l}\text { Pouca cobertura } \\
\text { populacional; } \\
\text { primeiros } \\
\text { estágios da } \\
\text { UHC. }\end{array}$ & $\begin{array}{l}\text { Parcela significativa } \\
\text { da população } \\
\text { conquista acesso } \\
\text { aos serviços com } \\
\text { proteção financeira, } \\
\text { mas a população } \\
\text { coberta ainda } \\
\text { não é universal e } \\
\text { permanece a falta } \\
\text { de acesso aos } \\
\text { serviços e à proteção } \\
\text { financeira. }\end{array}$ & $\begin{array}{c}\text { A cobertura } \\
\text { universal foi } \\
\text { atingida, mas } \\
\text { os países estão } \\
\text { focalizando } \\
\text { na melhora } \\
\text { da proteção } \\
\text { financeira e da } \\
\text { qualidade dos } \\
\text { serviços. }\end{array}$ & $\begin{array}{c}\text { Cobertura } \\
\text { universal } \\
\text { sustentável, } \\
\text { com acesso } \\
\text { amplo aos } \\
\text { serviços } \\
\text { e efetiva } \\
\text { proteção } \\
\text { financeira. }\end{array}$ \\
\hline Países & $\begin{array}{l}\text { Bangladesh e } \\
\text { Etiópia }\end{array}$ & $\begin{array}{c}\text { Gana, Indonésia, } \\
\text { Peru, Vietnã }\end{array}$ & $\begin{array}{l}\text { Brasil, Tailândia e } \\
\text { Turquia }\end{array}$ & França e Japão \\
\hline
\end{tabular}

Talvez o ponto que - independentemente da adoção da fórmula seguro de saúde ou da adoção do direito à saúde como um valor fundamental a ser assegurado por toda a sociedade para toda a sociedade por meio dos impostos - mereça atenção especial seja aquele relativo aos recursos humanos para a saúde. Com efeito, todos os países estudados possuem sérios problemas nesse campo, o que pode inviabilizar tanto a adoção quanto a sustentação de programas de cobertura universal. Isso exige um grande esforço regulátorio, com a criação, por exemplo, de mecanismos de formação mais curtos, de modo que o profissional esteja disponível em pouco tempo - como o caso dos agentes comunitários de saúde no Brasil, ou das enfermeiras práticas no Japão. Exige também um grande esforço na definição de carreiras atraentes, que incluam um tempo/serviço em zonas desprovidas de recursos, tais como as rurais. Os países precisam também investir na educação continuada de seus profissionais de saúde - garantindo o conhecimento necessário e a motivação dos profissionais - e na disponibilidade dos suprimentos e da infraestrutura básicos para que os serviços prestados atendam aos padrões mínimos de qualidade do cuidado em saúde. 
E um último ponto a ser ressaltado é que, apesar da franca opção pelo modelo mercadológico para a UHC, foram apresentadas as grandes dificuldades da adoção do seguro - especialmente aquelas relacionadas à construção de carteiras com a necessária diversidade de riscos para que sejam economicamente viáveis e efetivamente se responsabilizem pela ampla cobertura sanitária da população. Reconhece-se, assim, o problema da crescente camada populacional sem cobertura de saúde tanto na França quanto no Japão.

Em suma, Universal Health Coverage for Inclusive and Sustainable Development: A Synthesis of 11 Country Case Studies é uma obra interessante, oferecendo um panorama global de como o tema vem sendo abordado nos diferentes países. Ela exige, contudo, uma leitura competente, capaz de separar o viés ideológico adotado das informações objetivas, muito necessárias à apreciação da questão, uma vez que o debate a respeito da cobertura universal de saúde ainda carece de dados.

\section{Referências}

ABE, Shinzo. Comment: Japan's strategy for global health diplomacy: why it matters. The Lancet, v. 382, n. 9896, p. 915-916, 14 sep. 2013.

HORTON, Richard. Offline: The advantages of Universal Health. The Lancet, v. 30, n. 9854, p. 1632,10 nov. 2012.

ORGANIZAÇÃO DAS NAÇÕES UNIDAS (ONU). Assembleia Geral (67, 2012). Adopting consensus text, General Assembly encourages member states to plan, pursue transition of national health care systems towards universal coverage. (GA/11326) Dec 12, 2012. Disponível em: $<$ http://www.un.org/News/Press/docs/2012/ga11326.doc.htm2>.

Sueli Gandolfi Dallari - Professora Titular da Faculdade de Saúde Pública da USP; Coordenadora Científica do Núcleo de Pesquisa em Direito Sanitário da Universidade de São Paulo. Advogada. São Paulo/SP, Brasil.E-mail: sdallari@usp.br. 